\title{
Patient access to care- a need for mental health leadership, and a role for industry
}

A recent report from the Royal College of Psychiatrists has called for greater parity between mental and physical health. ${ }^{1}$ Central to this call is the concept of inequity, and under funding for mental health, with a specific emphasis on access to care and a reduction in the "mental health treatment gap". Support for such a call is emphasized by data from a recently published study documenting trends in life expectancy for psychiatric patients compared to a non psychiatric population - specifically that the life expectancy gap has increased for both male and female psychiatric patients i.e. that years lived are less for a psychiatric population, with the gap increasing between the 1985 and 2005. ${ }^{2}$ These findings were noteworthy in that physical illness accounted for $77.7 \%$ of excess death in psychiatric patients, with suicide accounting for $13.9 \%$. The suggestion is thus that resources for mental health need to include those for physical health.

One of the core components required is funding which ultimately speaks to resource allocation. The underfunding of psychiatric and related services potentially represents a form of stigma (which I choose to call "structural/institutional") that fails to recognize the resource requirements necessary to provide a holistic service for those who are mentally ill. A South African study reported on such inequity within the context of funding for psychiatric services relative to extent of clinical service delivery in a general hospital setting documenting significant under funding. ${ }^{3}$ Most recently the South African Department of Health told the South African parliament that three quarters of people with mental illness in South Africa receive inadequate care. ${ }^{4}$

An existing physician charter related to medical professionalism calls for "Commitment to improving access to care" as one of its "professional responsibilities" whereby "Physicians must individually and collectively strive to reduce barriers to equitable health care." Leadership is key in driving a process of achieving equity, both as individual professionals and as members of cohesive and representative professional bodies. The idea of mental health leadership to address institutional stigma is not novel, and organizations such as the Centre for Global Mental Health (who will be hosting their inaugural Forum in September 2013) are active in their pursuit of achieving parity between mental and physical health http://www.centreforglobalmentalhealth.org/.

Correspondence

Prof CP Szabo

email: christopher.szabo@wits.ac.za
Whilst such an organization brings a much needed focus, it is at a local level where the struggle is both acutely felt and needing to be addressed. The current editorial seeks to raise the issue of mental health leadership, as well as consider such an initiative funded by the pharmaceutical industry which within the context of corporate social investment - constitutes a public-private partnership emanating from within the public sector but funded by the private sector. The relationship between the pharmaceutical industry and physicians is one that requires careful consideration, specifically to ensure that at the heart of all such interactions patient care is central. ${ }^{6}$

A cynical view would be that no industry agendas can be truly altruistic as they occur within the context of profit. However, there may be exceptions. One such example would be where a pharmaceutical company initiates and promotes programmes that seek to facilitate government spending on mental health - with equitable access to care being a case in point. Prejudice against psychiatric patients is an age old phenomenon, and notwithstanding an increasing emphasis on human rights with an entrenchment of such rights in law, stigma remains. ${ }^{7,8}$ This can take numerous forms, the most obvious being in the social and occupational realms. However one cannot ignore the professional and "structural" components. The former relates to how psychiatrists are perceived by fellow specialists in other medical disciplines, with the latter reflecting, for example, institutional or/and governmental attitudes. Either of these components might influence the extent to which mental health is prioritized, and accordingly adequately resourced and funded - with resource allocation potentially a proxy for such attitudes.

If a pharmaceutical company were to fund an initiative whose objective was to address "structural" stigma through developing mental health leadership, would that fall within the realms of altruism whereby, whilst emanating from a profitable organization, the initiative did not either directly or indirectly seek to promote sales of product? This is the question and ultimately the potential dilemma, if one subscribes to the "no free lunch" belief.

The idea of private-public partnerships is one that is increasingly promoted in order to secure the involvement of private enterprise funding in facilitating implementation of public sector projects. Those with means benefit those without. In promoting such projects there is a win-win situation whereby corporate social initiatives contribute to improved welfare for those in need - without an ulterior motive. One cannot argue that profit is an industry driver, but we may see a time where profit is not all that drives 
industry, and that such an understanding enables a more collaborative relationship without the spectre of ulterior motives. Given resource issues in the developing world, such a relationship would be a highly attractive one. Ultimately, if patients benefit does it matter who contributes financially to such benefit? The debate has been rather polarized to date. Checks and balances are necessary in any relationship, especially where there are vested interests of a financial nature and the possibility of exploitation exists. In the ongoing debate about the industry-clinician relationship, the patient should not be forgotten. In funding mental health leadership programmes, for example, the discipline will be strengthened and patients will ultimately benefit. A recent editorial by Parker, Allen and Lund called for consideration of a public mental health component in specialist training, with a specific emphasis on reducing the "mental health treatment gap". ${ }^{9}$ Such sentiment accords with a mental health leadership initiative, which serves as the basis for this editorial. If deemed of benefit it would then serve as a basis for roll out to a wider specialist and specialist trainee group at a national (South Africa) level, and beyond - but potentially without further industry support as educational institutions and/or professional bodies incorporate such capacity building into teaching programmes. Psychiatry needs to acknowledge that whilst structural/institutional stigma may well exist, the discipline needs to move beyond identifying such stigma and develop ways of addressing it. The capacity to engage strategically would appear to be a necessary component, and echoes one of the key objectives highlighted in the recently released Comprehensive Mental Health Action Plan 20132020 adopted by the World Health Assembly on May 27, 2013 i.e. leadership. However, beyond the aforementioned Plan's referral to Ministries of Health with regard to leadership, the current initiative seeks to develop capacity amongst those directly involved in patient care-clinicians. ${ }^{10}$

\section{Acknowledgement}

Prof. Szabo attended a sanofi sponsored Mental Health Initiative meeting held in Ho Chi Minh City, Vietnam (September 201 1). Projects involving industry-government collaboration related to access to care were discussed with the possibility of future projects being developed. Subsequent to the meeting, Prof. Szabo conceived and together with Dr Fine (sanofi) developed a mental health leadership initiative, funded by sanofi. The initiative led to a workshop (April 2013) comprising didactic teaching on ethics, law, human rights, leadership and Government approaches to resource allocation - within a South African context. Participants were selected nationally, based on existing efforts/projects to acquire resources for patient care. Each project was reviewed, and will receive active mentoring to facilitate progress. 6 monthly review during the subsequent 18 months will take place as part of the initiative. The editorial was not solicited by the company in question, although Dr Fine did comment on preliminary content and did submit final content to sanofi as part of company requirements. The editorial is intended to document the initiative and promote discussion/debate rather than support a given position.

CP Szabo

Division of Psychiatry, Faculty of Health Sciences, University of the Witwatersrand, Johannesburg, South Africa

\section{References}

1. Wise J. Report calls for mental health to have parity with physical health. British Medical Journal 2013;346:f1 973 doi:10.1136/bmj.f1 973

2. Lawrence D, Hancock KJ, Kisely S. The gap in life expectancy from preventable physical illness in psychiatric patients in Western Australia: retrospective analysis of population based registers. British Medical Journal 2013; 346. doi:http://dx.doi.org/10.1136/bmj.f2539

3. Janse van Rensburg AB, Jassat W. Acute mental health care according to recent mental health legislation Part II. Activity-based costing. African Journal of Psychiatry 2011;14(1):23-9.

4. Kahn T. Most people with mental disorders 'not getting care they need'. Business Day 13 th June 2013, p4.

5. Project of the ABIM Foundation, ACP-ASIM Foundation, and European Federation of Internal Medicine. Medical Professionalism in the New Millennium: A Physician Charter. Annals of Internal Medicine 2002;136(3):243-246. doi:10.7326/0003-4819-136-3200202050-00012

6. Collins J. Professionalism and physician interactions with industry. Journal of the American College of Radiology 2006; 3(5):325-32.

7. Beldie A, den Boer JA, Brain C, Constant E, Figueira ML, Filipcic I, et al. Fighting stigma of mental illness in midsize European countries. Social Psychiatry and Psychiatric Epidemiology 2012;47 Suppl 1:138. doi: 10.1007/s00127-012-0491-z.

8. Lauber C, Rössler W. Stigma towards people with mental illness in developing countries in Asia. International Review of Psychiatry 2007; 19(2):157-78.

9. Parker JS, Allen RR, Lund C. Are we training our psychiatrists adequately as public mental health practitioners ? S Afr J Psych 2013; 19(1):2-3. doi:10.7196/SAJP.431

10. Saxena S, Funk M, Chisholm D. World Health Assembly adopts Comprehensive Mental Health Action Plan 2013-2020. The Lancet 2013; 381: 1970-1971. 